\title{
Sonographic measurement of normal plantar fascia thickness in healthy nepalese population
}

BACKGROUND: Plantar fascitis is one of the commonest causes of heel pain. Thickening of plantar fascia is the most consistent sonological finding in plantar fasciitis.

Objective: To estimate normal plantar fascia thickness in healthy Nepalese volunteers and evaluate its relationship with age, sex, height, weight and body mass index (BMI).

METHODS: The plantar fascia thickness was measured at $5 \mathrm{~mm}$ distal to its insertion into the calcaneus using $10 \mathrm{MHz}$ linear array transducer. Total 700 feet of 350 healthy volunteers were evaluated in our study. Physical examination was also performed to assess height, weight and BMI.

RESULTS: The mean plantar fascia thickness among entire population, male subjects, female subjects, right side and left side were respectively $2.39 \pm 0.37$ (Range 1.4-3.6; 95\% confidence interval $=2.36-2.42) ; \quad 2.47 \pm 0.37$ (Range 1.4-3.6; 95\% confidence interval $=2.43-2.51$ ); 2.32 \pm 0.35 (Range 1.4-3.5; 95\% confidence interval $=2.28-2.36) ; 2.39 \pm 0.36$ (Range 1.4-3.6; 95\% confidence interval $=2.35-2.43$ ) and 2.40 \pm 0.37 (Range 1.4-3.5; $95 \%$ confidence interval of $2.36-2.44)$. The mean was significantly higher in men than in women $(p<0.05)$ but similar in left and right feet $(p>0.05)$. Amongst age, sex, weight, height and body mass index; only age significantly co-related with the plantar fascia thickness.

CONCLUSION: The mean plantar fascia thickness was $2.39 \pm 0.37 \mathrm{~mm}$. The mean is significantly higher in men than in women but similar in both feet. Sex, weight, height and BMI are not significantly related to the thickness. Age is the single most determinant factor of plantar fascia thickness.

Key Words: Plantar fascia, Thickness, Sonography

\section{INTRODUCTION:}

Heel pain is a common complaint often seen in orthopedic clinics. However, it is imperative that the orthopedic surgeon understands the multiple causes of plantar foot pain and is able to differentiate the multiple causes of heel pain to confirm a specific diagnosis and formulate a proper treatment plan. Apart from thorough history and clinical examination, diagnostic procedures are sometimes necessary. ${ }^{1}$ Plantar fascitis is a common cause of heel pain. The diagnosis is made clinically and validated with different diagnostic modalities ranging from ultrasound to magnetic resonance imaging. ${ }^{2}$ Although MRI is the modality of choice in the morphologic assessment of different plantar fascia lesions, sonography can also serve as an effective 
tool and may substitute MRI in the diagnosis of plantar fasciitis. ${ }^{3}$ Moreover, ultrasonographic examination of plantar fascia is easy and quick to perform. It is well recognized that increased plantar fascia thickness and hypoechoic texture are sonographic features of plantar fasciitis. ${ }^{4,5,6}$ Accordingly several studies have been made in the past concerning sonographic evaluation of normal plantar fascia, ${ }^{9,8}$ and plantar fascitis. ${ }^{3,9,10}$ But most of them are based on the data from Western population. With so many differences in lifestyles, economic status, working environment and geographic variation, we predict that there must be differences in plantar fascia thickness among Nepalese population from that of Western world. The current study was undertaken to define normal plantar fascia thickness in healthy Nepalese population and its relationship with age, sex, height, weight and BMI.

\section{METHODS:}

This was a prospective study conducted in a University Hospital after obtaining approval from the hospital ethics committee. The inclusion criteria were normal healthy subjects with no present or past history of heel pain. The cases with sonographic abnormalities such as calcified, thickened or hypoechoic plantar fascia was excluded from the study. Hence final study population constituted 350 healthy volunteers. Among these, 166 were male subjects and the rest 184 were female subjects. The youngest healthy volunteer was 15years and the oldest one was 86years old. Ultrasonographic measurements were made by a real-time system with a $10 \mathrm{MHz}$ linear transducer (ACUSON X150, Mountain View, CA 94043 USA). The plantar fascia thickness was measured at $5 \mathrm{~mm}$ distal to its insertion into the calcaneus (Fig 1). To increase the reliability as advised by Skovdal et $\mathrm{al}^{11}$, three measurements were taken at the same place and mean of the three were taken as final. In addition to this, physical examination was also performed to assess height, weight and BMI.

The statistical analyses were performed by SPSS software version 11.5. Results were expressed as mean \pm standard deviation. The average plantar fascia thickness, standard deviation and 95\% confidence interval were assessed among entire population, males subjects, female subjects, right side and left side. Paired t test was used to assess significant differences within group. Continuous variables were compared using parametric tests. Pearson correlation coefficients were used to determine correlations between plantar fascia and age, sex, weight, height and BMI. Finally multivariate regression analysis performed to estimate the coefficients of the linear equation, involving the above mentioned independent variables that best predict the value of the dependent variable i.e, plantar fascia.

\section{RESULTS:}

A total of 700 feet in 350 healthy asymptomatic subjects (male and female) were enrolled in this study. The mean plantar fascia thickness was 2.39 \pm 0.37 (Range 1.4-3.6). 95\% confidence interval was 2.36-2.42. The mean plantar fascia thickness among male subjects was $2.47 \pm 0.37$ (Range 1.4-3.6) with $95 \%$ confidence interval of 2.43-2.51. The mean plantar fascia thickness among female subjects was $2.32 \pm 0.35$ (Range 1.43.5) with $95 \%$ confidence interval of 2.28-2.36. The mean plantar fascia thickness on right side was $2.39 \pm 0.36$ (Range 1.4-3.6) with $95 \%$ confidence interval of 2.35-2.43. The mean plantar fascia thickness on left was 2.40 \pm 0.37 (Range 1.4-3.5) with 95\% confidence interval of 2.36-2.44. (Table I)

The mean value of PF were significantly higher in men than in women $(p<0.05)$. The mean value of PF were similar in left and right feet ( $p>0.05)$ (Table II) .

All five factors viz, age, sex, weight, height and BMI were mildly related to PF thickness $(p<0.05)$ which we have taken $5 \mathrm{~mm}$ distal to the insertion point (Table III). Results of multivariate regression analysis showed PF thickness at $5 \mathrm{~mm}$ distal to the insertion was associated with age as predictor variable (Table IV).

\section{DISCUSSION:}

Plantar fascia or plantar aponeurosis, is the strong, fibrous investing layer of the sole of the foot. ${ }^{12}$ It is considered a major contributor to arch support. ${ }^{13,14,15}$ Plantar fascia is affected by various 
pathologic conditions viz; plantar fasciitis, plantar fibroma, plantar fascia rupture. ${ }^{16,17}$ Plantar fasciitis is one of the most common causes of heel pain. ${ }^{18}$ The diagnosis is made clinically and validated with different diagnostic modalities ranging from ultrasound to magnetic resonance imaging. ${ }^{19} \mathrm{MR}$ imaging reliably delineates the anatomy of the plantar aponeurosis and may allow precise localization and definition of the extent of involvement in disease processes. ${ }^{20}$ Being cheap, widely available and due to good sensitivity and specificity and free radiation; ultrasound has become the first line imaging modality for the evaluation of plantar fasciitis. ${ }^{21}$ Ultrasound-guided injection is effective in the management of plantar fasciitis and may be used as an objective measure of response to treatment in plantar fascitis. ${ }^{22}$ There

Ozdemir et $\mathrm{al}^{25}$ measured plantar fascia thickness $5 \mathrm{~mm}$ distal to the insertion of the calcaneus of plantar aponeurosis and found mean thickness of $2.5 \mathrm{~mm}$ in control healthy volunteers $(n=22)$. The mean plantar fascia thickness was $2.4 \pm 0.64$ in healthy subjects in their study of Kamel et $\mathrm{al}^{23}$. However they have not specified the exact landmark of measurement. Cardinal et $\mathrm{al}^{9}$ measured plantar fascia thickness at its proximal end near its insertion into the calcaneus in both the feet of 15 healthy volunteers and found mean thickness of $2.6 \mathrm{~mm} \pm 1.13$ with a range of $1.6-3.8 \mathrm{~mm}$. Due to lack of standardized measurement, Pascual et $\mathrm{al}^{8}$ in their extensive study measured plantar fascia at four different locations viz; $1 \mathrm{~cm}$ proximal to the insertion, at the insertion, $1 \mathrm{~cm}$ and $2 \mathrm{~cm}$ distal to its insertion site. The mean thickness was variable in all the locations; $1.99 \pm 0.65$ at $1 \mathrm{~cm}$ proximal to the insertion point, $3.33 \pm 0.69 \mathrm{~mm}$ at insertion, $2.7 \pm 0.69 \mathrm{~mm}$ at $1 \mathrm{~cm}$ distal from the insertion and are various sonographic features of plantar fasciitis viz; thickening , decreased echogenicity, calcification of the fascia and perifascial fluid collection. 9,10,16,23 One study even showed power Doppler improving the value of ultrasound as a noninvasive technique for the diagnosis of plantar fasciitis, providing additional information on local hyperemia. ${ }^{24}$ Among these; thickening of plantar fascia has been shown as the most consistent feature of plantar fasciitis in most of the studies. Hence plantar fascia thickness is an important parameter in the evaluation of plantar fasciitis. This necessitates the assessment of baseline or normal plantar fascia thickness in general population. Various studies in the past have assessed plantar fascia thickness in a wide variety of ways.

$2.64 \pm 0.69 \mathrm{~mm}$ at $2 \mathrm{~cm}$ distal from the insertion. They found statistically significant differences in plantar fascia thickness at these four different locations. We have taken $5 \mathrm{~mm}$ distal to its insertion as a landmark of measurement due to easy delineation of the parallel fascial margins. This makes us easy to measure the plantar fascia and get more consistent and accurate measurement unlike at the origin where the fascial margins are not parallel. Moreover, Uzel et $\mathrm{al}^{7}$ did not find differences in PF thickness at two different locations (origin and $5 \mathrm{~mm}$ distal from origin). Several studies ${ }^{25}, 26$ have also taken this as a landmark for measurement of plantar fascia and hence evaluation of plantar fasciitis. Pascual et $\mathrm{al}^{8}$ speculated that PF thickness is quite variable at its proximal part in asymptomatic subjects but tends to be more regular distally which could be a good indicator of global thickness of plantar fascia in healthy subjects.

The mean plantar fascia thickness in our study was $2.39 \pm 0.37 \mathrm{~mm}$. This was in comparison to the study by Ozdemir et $\mathrm{al}^{25}$ and Kamel et $\mathrm{al}^{23}$ in their normal control subjects; but lower than those in the study by Uzel et $\mathrm{al}^{7}$ and Pascual et al. ${ }^{8}$ To our knowledge, the sample size (total feet $=700$ ) is highest among all previous studies. This further validates our observation. Also differences in lifestyles, economic status, working environment and geographic variation must have influenced the plantar fascia thickness in our population. With such baseline fascial thickness, further study thus can be performed in symptomatic people with heel pain in our population to find out cutoff fascial thickness to diagnose plantar fasciitis. This cut off plantar fascia thickness in plantar fasciitis is again variable among various studies. Wall et $\mathrm{al}^{26}$ found that the mean PF thickness was $5.7 \pm 1.6 \mathrm{~mm}$ at a distance of $0.5 \mathrm{~mm}$ distal to the anterior edge of medial tubercle of the calcaneus in patients with plantar fasciitis. Karabay et $\mathrm{al}^{27}$ found mean plantar fascia thickness of $4.79 \mathrm{~mm}$ in symptomatic feet. Slightly altered result was seen in the study by Akfirat et $a^{21}$ where the mean fascial thickness was $4.75 \pm 1.52 \mathrm{~mm}$ in symptomatic heels. Hence separate study is necessary in our population to delineate cutoff fascial thickness in a large number of symptomatic people for the diagnosis of plantar fasciitis.

Other observations in our study were significantly higher mean value of PF in men than in women $(p<0.05)$. 


\section{Original Article}

This could be explained by an anatomical difference in gender. But similar mean value of PF in left and right feet $(p>0.05)$ could be explained by the fact that both the feet are used equally in our daily activities unlike upper limbs which could be influenced by handedness of the individual. Both the observations were consistent with the study by Uzel et al. ${ }^{7}$ All five variables viz; age, sex, weight, height and BMI were mildly correlated with PF thickness and were significant at $<0.001$ level. This is slightly variable to the study by Uzel et $\mathrm{al}^{7}$ who found moderate correlation between PF and weight, height and BMI. Pascual et $\mathrm{al}^{28}$ also found moderate correlation of BMI with plantar fascia thickness.

Initial univariate regression analysis showed that all the five variables were predictors of PF thickness. However, multivariate regression analysis revealed that weight was not the predictive factor of PF thickness. This is in contradiction with the study by Pascual et $\mathrm{al}^{8}$ who found weight as a predictive value of PF thickness at $1 \mathrm{~cm}$ distal to its insertion. Only one explanation, we thought, can be given to this varied result in our study. Most of the individuals in our study have light body weight (Mean weight in our study group was 56kilograms). Thus, the light body weight, we believe, perhaps does not have much influence on plantar fascia thickness compared to large body weight.

In the study by Pascual et $\mathrm{al}^{8}{ }^{8}$ age met the $\mathrm{p}<0.05$ criteria in the univariate regression however it did not emerged as significant in the multivariate analysis. On the contrary, we found age as an independent predictor of PF thickness at $5 \mathrm{~mm}$ distal to its origin in both univariate as well as multivariate regression analysis. We evaluated PF thickness of 700 feet among healthy subjects as young as 15 years and as old as 86years. We believe that continuous, long term biomechanical stress of the PF over years might influence its thickness. Hence age is the determinant factor of plantar fascia thickness.

\section{CONCLUSION:}

We got the mean plantar fascia thickness among healthy volunteers. This gives the baseline measurement for further study on plantar fasciitis in our population. The mean value of PF is significantly higher in men than in women. However, the mean value of PF is similar in left and right feet. Age, sex, weight, height and BMI are only mildly related to PF thickness. Body weight is not the determinant factor of PF thickness. But continuous, long term biomechanical stress of the PF over years might influence its thickness. Hence age is the determinant factor of plantar fascia thickness. 


\section{Original Article}

\section{References}

La Porta GA, La Fata PC. Pathologic conditions of the plantar fascia. Clin Podiatr Med Surg 2005;22(1):1-9.

Healey K, Chen K. Plantar fasciitis: current diagnostic modalities and treatments. Clin Podiatr Med Surg 2010;27(3):369-80.

Sabir N, Demirlenk S, Yagci B, Karabulut N, Cubukcu S. Clinical ultility of sonography in diagnosing plantar fasciitis. J Ultrasound Med 2005;24(8):1041-8.

Gill LH. Plantar fasciitis: Diagnosis and Conservative Management. J Am Acad Orthop Surg 1997;5(2):10917.

Cardinal E, Chhem RK, Beauregard CG, Aubin B, Pelletier M. Plantar fasciitis: sonographic evaluation. Radiology 1996;201(1):257-9.

Tsai WC, Chiu MF, Wang CL, Tang FT, Wong MK. Ultrasound evaluation of plantar fasciitis. Scan J Rheumatol 2000;29(4):255-9.

Uzel M, Cetinus E, Ekerbicer HC, Karaoguz A. The influence of athletic activity on the plantar fascia in healthy young adults. J Clin Ultrasound 2006;34(1):17-21.

Pascual HJ, Alarcon Garcia JM. Effect of gender, age and anthropometric variables on plantar fascia thickness at different locations in asymptomatic subjects. Eur J Radiol 2007;62(3):449-53.

Cardinal E, Chhem RK, Beauregard CG, Aubin B, Pelletier M. Plantar fasciitis: sonographic evaluation. Radiology 1996;201(1):257-9.

McMillan AM, Landorf KB, Barrett JT, Menz HB, Bird AR. Diagnostic imaging for chronic plantar heel pain: a systematic review and meta-analysis. J Foot Ankle Res 2009;2:32.

Skovdal RM, Moelqaard C, Lykkegaard OJ. Intra-and interobserver reliability of quantitative ultrasound measurement of the plantar fascia. J Clin Ultrasound 2011. [Epub ahead of print].

Sarrafian S. Plantar aponeurosis. In: Sarrafian S, eds. Anatomy of the foot and ankle: descriptive, topographic, functional. 2nd ed. Philadelphia, Pa: Lippincott, 1993; 137-49.

Thordarson DB, Schmotzer H, Chon J, Peters J.Dynamic support of the human longitudinal arch: a biomechanical evaluation. Clin Orthop 1995; 316:165-172.

Huang CK, Kitaoka HB, An KN, Chao EYS. Biomechanical evaluation of longitudinal arch stability. Foot Ankle 1993;14(6):353-7.

Kitaoka HB, Ahn TK, Luo ZP, An KN. Stability of the arch of the foot. Foot Ankle Int 1997;18(10):644-8.

McNally EG, Shetty S. Plantar fascia: imaging diagnosis and guided treatment. Semin Musculoskelet Radiol 2010;14(3):334-43.

Louwers MJ, Sabb B, Pangilinan PH. Ultrasound evaluation of a spontaneous plantar fascia rupture. Am J Phys Med Rehabil 2010:89(11):941-4.

Cornwall MW, McPoil TG. Plantar fasciitis: etiology and treatment. J Orthop Sports Phys Ther 1999; 29:75660.

Healey K, Chen K. Plantar fasciitis: current diagnostic modalities and treatments. Clin Podiatr Med Surg 2010;27(3):369-80.

Theodorou DJ, Theodorou SJ, Kakitsubata Y, et al. Plantar fasciitis and fascial rupture: MR imaging findings in 26 patients supplemented with anatomic data in cadavers. Radiographics 2000;20:S181. 


\section{Original Article}

Akfirat M, Sen C, Gunes T. Ultrasonographic appearance of the plantar fasciitis. J Clin Imag 2003;27(5):3537.

Kane D, Greaney T, Shanahan M, Duffy G, Bresnihan B, Gibney R et al. The role of ultrasonography in the diagnosis and management of idiopathic plantar fasciitis. Rheumatology 2001;40(9):1002-8.

Kamel $\mathrm{M}$, Kotob $\mathrm{H}$. Hight frequency ultrasonographic findings in plantar fasciitis and assessment of local steroid injection. J Rheumatol 2000;27(9):2139-41.

Walther M, Radke S, Kirschner S, Ettl V, Gohlke F. Power Doppler findings in plantar fasciitis. Ultrasound Med Biol 2004;30(4):435-40.

Ozdemir H, Yilmaz E, Murat A, Karakurt L, Poyraz AK, Ogur E. Sonographic evaluation of plantar fasciitis and relation to body mass index. Eur J Radiol 2005;54(3):443-7.

Wall JR, Harkness MA, Crawford A. Ultrasound diagnosis of plantar fasciitis. Foot Ankle Int 1993;14(8):46570.

Karabay N, Toros T, Hurel C. Ultrasonographic evaluation in plantar fasciitis. J Foot Ankle Surg 2007;46(6):442-6.

Pascual H J, Garcia JM, Matamoros EC, Matamoros JC, Martinez TD. Relationship of body mass index, ankle dorsiflexion, and foot pronation on plantar fascia thickness in healthy, asymptomatic subjects. J Am Podiatr Med Assoc 2008;98(5):379-85. 
Original Article

TABLE I: Plantar fascia thickness (5mm distal to insertion)

\begin{tabular}{|l|l|l|l|l|}
\hline & Mean & $\begin{array}{l}\text { Standard } \\
\text { Deviation }\end{array}$ & $\begin{array}{l}\text { 95\% Confidence } \\
\text { Interval }\end{array}$ & Range \\
\hline Sample(n=700) & 2.39 & 0.37 & $2.36-2.42$ & $1.4-1.36$ \\
\hline Male (332) & 2.47 & 0.37 & $2.43-2.51$ & $1.4-3.6$ \\
\hline Female(368) & 2.32 & 0.35 & $2.28-2.36$ & $1.4-3.5$ \\
\hline Right Heel (350) & 2.39 & 0.36 & $2.35-2.43$ & $1.4-3.6$ \\
\hline Left Heel (350) & 2.40 & 0.37 & $2.36-2.44$ & $1.4-3.5$ \\
\hline
\end{tabular}

TABLE II: Paired Samples Test

\begin{tabular}{|c|c|c|c|c|c|c|}
\hline \multirow{3}{*}{ Pair Samples } & \multicolumn{5}{|c|}{ Paired Differences } & \\
\hline & \multirow[t]{2}{*}{ Mean } & \multirow[t]{2}{*}{$\begin{array}{l}\text { Std. } \\
\text { Deviation }\end{array}$} & \multirow[t]{2}{*}{$\begin{array}{l}\text { Std. } \\
\text { Error } \\
\text { Mean }\end{array}$} & \multicolumn{2}{|c|}{$\begin{array}{l}95 \% \text { Confidence } \\
\text { Interval of the } \\
\text { Difference }\end{array}$} & \\
\hline & & & & Lower & Upper & $P$ value \\
\hline Pair $1 \quad$ RIGHT PF - LEFT PF & -.006 & .2067 & .0110 & -.028 & .016 & .587 \\
\hline Pair 2 FEMALE PF-MALE PF & -.144 & .5149 & .0283 & -.200 & -.089 & .000 \\
\hline
\end{tabular}

TABLE III: Relationship of plantar fascia (5mm distal to insertion) with age, sex, weight, height and BMI

\begin{tabular}{|l|l|l|}
\hline & $r$ & $p$ \\
\hline Age Group & 0.135 & $<0.001$ \\
\hline Sex & -0.204 & $<0.001$ \\
\hline Weight & 0.276 & $<0.001$ \\
\hline Height & 0.184 & $<0.001$ \\
\hline BMI & 0.195 & $<0.001$ \\
\hline
\end{tabular}




\section{Original Article}

TABLE IV: Multivariate regression analysis

\begin{tabular}{|l|l|l|}
\hline Predictors & Beta coefficient & P value \\
\hline Age & 0.095 & 0.014 \\
\hline Sex & -0.77 & 0.129 \\
\hline Weight & 0.312 & 0.416 \\
\hline Height & -0.031 & 0.891 \\
\hline BMI & -0.073 & 0.825 \\
\hline
\end{tabular}

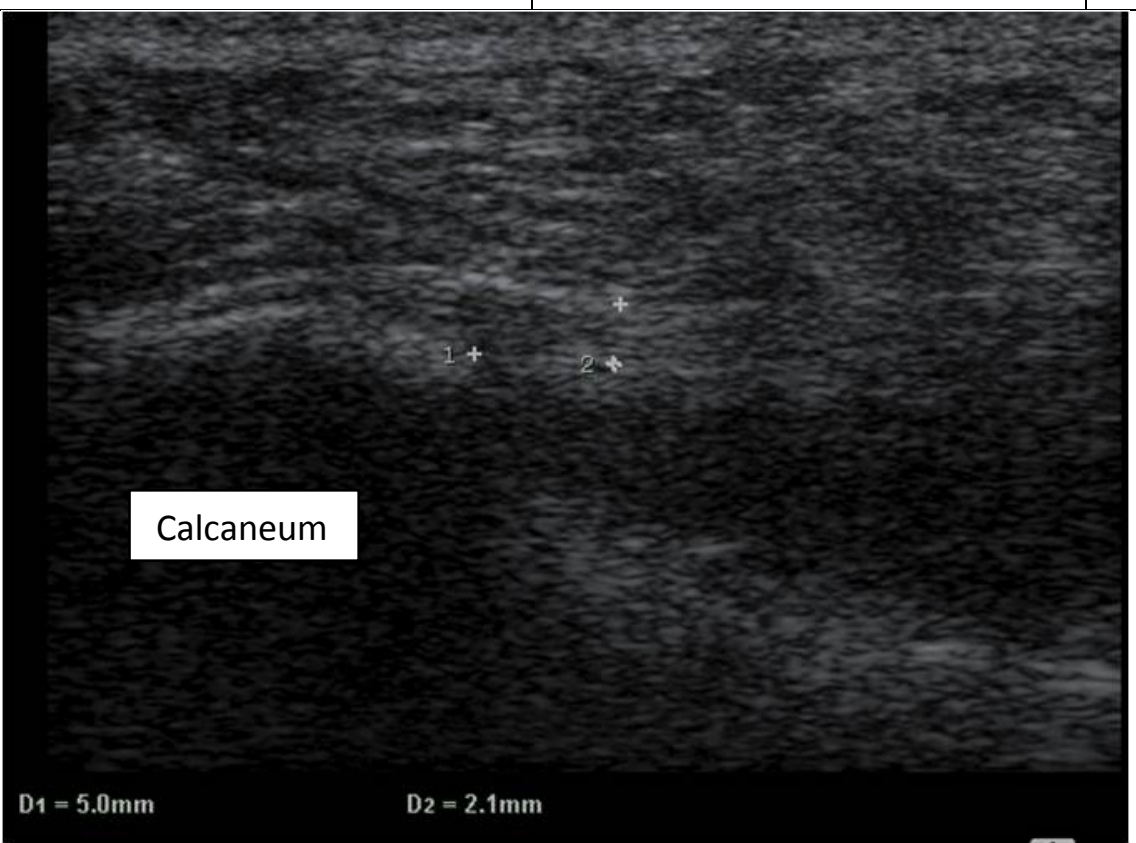

Fig 1. Sonogram depicts plantar fascia thickness (cursors) at $5 \mathrm{~mm}$ distal to its insertion point.

1+ : point of insertion. 2+: landmark of measurement. 